\title{
Benefits of omitting chest drain after thoracoscopic major lung resection
}

\author{
Mateja Ladan, René Horsleben Petersen \\ Department of Cardiothoracic Surgery, Rigshospitalet, Copenhagen, Denmark \\ Correspondence to: René Horsleben Petersen, MD, PhD. Chief Thoracic Surgeon, Clinical Associate Research Professor, Department of \\ Cardiothoracic Surgery, Copenhagen University Hospital, Rigshospitalet, Blegdamsvej 9, 2100, Copenhagen, Denmark. \\ Email: Rene.Horsleben.Petersen@regionh.dk. \\ Provenance: This is an invited article commissioned by the Academic Editor Dr. Shuangjiang Li (Department of Thoracic Surgery and West China \\ Medical Center, West China Hospital, Sichuan University, Chengdu, China). \\ Comment on: Ueda K, Haruki T, Murakami J, et al. No drain after thoracoscopic major lung resection for cancer helps preserve the physical function. \\ Ann Thorac Surg 2019;108:399-404.
}

Submitted Nov 01, 2019. Accepted for publication Nov 17, 2019.

doi: $10.21037 /$ jtd.2019.11.76

View this article at: http://dx.doi.org/10.21037/jtd.2019.11.76

The usage of chest drains after thoracic surgery was first reported in 1922 and has been a routine part of the procedures since the 1950s (1). Aside from draining the pleural cavity of air and excess fluid, the indication for chest drains is to prevent a possible pneumothorax from evolving into a pressure pneumothorax and to help and guide the surgeons in the decision making of the need for redosurgery.

Over the last couple of decades, thoracic surgery, like many other surgical specialties, has been evolving towards less invasive methods. Hence the introduction of videoassisted thoracoscopic surgery (VATS) lobectomy in the early 1990s (2). This shift towards less surgical trauma has led to increased focus on the chest drain induced "trauma", as there are well known adverse effects with chest drains such as pain, increased risk of infections, impaired pulmonary function and prolonged hospital stay (3-5). The past couple of decades the trend has thus gone from the previous standard of double chest drains placed in the apical and basal positions after standard lobectomy to a single chest drain. A randomized controlled trial has shown this strategy to be superior (6). The latest studies focusing on post-surgical chest drain management have examined the effects of omitting drainage completely in select patients, however mostly in patients that have undergone wedge resection (7-10).

Ueda and colleagues from Yamaguchi University in Japan have in a previous study shown that omitting postoperative chest tube drainage in selected patients undergoing thoracoscopic major lung resection is not only feasible but reduces postoperative pain and length of stay (LOS) (11). In the current study they aimed to examine whether the omission of postoperative chest drain in patients undergoing thoracoscopic major lung resection for primary lung cancer had some further advantages, more precisely if it helped preserve the pulmonary function capacity and increased the walking distance. Also in this study they examined whether there was a reduction in pain, use of analgesics and LOS (12). The study is a retrospective review on prospectively collected data from 116 patients. They mention that whether or not chest tube drainage was to be inserted was determined based on predefined criteria. However, apart from intraoperative confirmation test for pneumatosis, they do not describe what these criteria are. They found an increased vital capacity, increased 6-minute walking distance and reduced pain measured on POD-1 correlated with omission of chest drains, which are important advantages for patients. This study indicate that omitting chest drain in selected patients undergoing thoracoscopic major lung resection is not only safe, but also beneficial. Hence, ultimately out-patient surgery of some lung cancer patients could be a plausible goal.

The study however has some shortcomings. Mainly it is not a randomized study and there is a risk of potential 
selection bias between the groups. The authors imply that a randomized study would be difficult to perform as they have already proven the feasibility of omitting chest tube after major lung resection. Another shortcoming with the study is that the authors, did not provide firm selection criteria for when to omit chest drains, which also leaves room for bias and cofounders. Furthermore, the walking distance was dependent on the VAS rather than directly on the presence or absence of chest tube and all outcomes where related to each other.

Our research group published a feasibility study in 2016 showing that chest drain omission after thoracoscopic pulmonary wedge resection in selected patients is safe. We used rather rigid selection criteria for omitting chest drains; Forced expiratory volume in $1 \mathrm{~s}$ (FEV1) $>60 \%$ of expected, FEV1/forced vital capacity $>70 \%$, tumour diameter $<2 \mathrm{~cm}$, distance from tumour to visceral pleura $<3 \mathrm{~cm}$, less than 2 separate wedges, no air leak on an intraoperative air leakage test and absence of severe adhesions, bullous/emphysematous disease, pleural effusion and coagulopathy (7). These criteria may be too narrow, however further studies are needed to select the target group.

The complication profile in wedge resections and major lung resection are somewhat different. Significant bleeding after VATS-lobectomies occurs with an incident of 1-2\% (13). A relevant question is therefore how to best monitor postoperative patients for this possible complication without the direct insight that a chest drain provides. In our study from 2016 all patients were referred to a PACU unit for 2-3 hours initial observation by trained nurses and two postoperative $\mathrm{X}$-rays were done, one 1-2 hours postoperatively and another 8 hours after surgery, in order to elucidate occult bleeding. Ueda et al. do not mention their approach to postoperative monitoring.

The authors remark that performing a randomized study will be difficult, considering the proven feasibility of omitting chest tube after major lung resection. However, we argue that, as chest tube placement is still the gold standard for major lung resection in most centers, a randomized study is not only possible, but also necessary in order to exclude biases and confounders before drawing a conclusion of the benefits of omitting chest tube drain in this group of patients and to answer some of above posed questions.

In conclusion, this innovative study from Yamaguchi University in Japan further implies the benefits of the trend towards omitting chest drains in lung surgery for selected patients, which, if proven safe and beneficial, can lead to the practice of out-patient surgery for lung cancer patients.
This study is however, like previous preliminary studies, not enough to draw firm conclusions. A large-scale multicenter randomized study is needed to establish firm evidence for omitting chest drains.

\section{Acknowledgments}

None.

\section{Footnote}

Conflicts of Interest: RH Petersen has received speaker fee from Medtronic. M Ladan has no conflicts of interest to declare.

Ethical Statement: The authors are accountable for all aspects of the work in ensuring that questions related to the accuracy or integrity of any part of the work are appropriately investigated and resolved.

\section{References}

1. Venuta F, Diso D, Anile M, et al. Chest Tubes: Generalities. Thorac Surg Clin 2017;27:1-5.

2. Roviaro G, Rebuffat C, Varoli F, et al. Videoendoscopic pulmonary lobectomy for cancer. Surg Laparosc Endosc 1992;2:244-7.

3. Mao M, Hughes R, Papadimos TJ, et al. Complications of chest tubes. Curr Opin Pulm Med 2015;21:376-86.

4. Refai M, Brunelli A, Salati M, et al. The impact of chest tube removal on pain and pulmonary function after pulmonary resection. Eur J Cardiothorac Surg 2012;41:820-2; discussion 823.

5. Bardell T, Petsikas D. What keeps postpulmonary resection patients in hospital? Can Respir J 2003;10:86-9.

6. Zhou D, Deng XF, Liu QX, et al. Single chest tube drainage is superior to double chest tube drainage after lobectomy: A meta-analysis. J Cardiothorac Surg 2016;11:88.

7. Holbek BL, Hansen HJ, Kehlet H, et al. Thoracoscopic pulmonary wedge resection without post-operative chest drain: an observational study. Gen Thorac Cardiovasc Surg 2016;64:612-7.

8. Watanabe A, Watanabe T, Ohsawa H, et al. Avoiding chest tube placement after video-assisted thoracoscopic wedge resection of the lung. Eur J Cardiothorac Surg 2004;25:872-6.

9. Luckraz H, Rammohan KS, Phillips M, et al. Is an 
Intercostal Chest Drain Necessary After Video-Assisted Thoracoscopic (VATS) Lung Biopsy? Ann Thorac Surg 2007;84:237-9.

10. Ueda K, Hayashi M, Tanaka T, et al. Omitting chest tube drainage after thoracoscopic major lung resection. Eur J Cardiothorac Surg 2013;44:225-9; discussion 229.

11. Ueda K, Haruki T, Murakami J, et al. No drain after thoracoscopic major lung resection for cancer helps preserve the physical function. Ann Thorac Surg 2019;108:399-404.

Cite this article as: Ladan M, Petersen RH. Benefits of omitting chest drain after thoracoscopic major lung resection. J Thorac Dis 2019;11(12):5613-5615. doi: 10.21037/jtd.2019.11.76
12. Murakami J, Ueda K, Tanaka T, et al. The Validation of a No-Drain Policy After Thoracoscopic Major Lung Resection. Ann Thorac Surg 2017;104:1005-11.

13. Falcoz PE, Puyraveau M, Thomas PA, et al. Videoassisted thoracoscopic surgery versus open lobectomy for primary non-small-cell lung cancer: A propensitymatched analysis of outcome from the European Society of Thoracic Surgeon database. Eur J Cardiothorac Surg 2016;49:602-9. 